\title{
Role of monocyte and lymphocyte counts in prognosis of cervical cancer
}

\author{
Aanchal Jain*, Saurabh Bobdey, Jignasa Sathwara, B. Ganesh, \\ Sushma Saoba, Arshi Khan
}

Department of Medical Records, Biostatistics and Epidemiology, Tata memorial Hospital, Mumbai, Maharashtra, India

Received: 02 May 2016

Accepted: 02 June 2016

\section{*Correspondence:}

Mrs. Aanchal Jain,

E-mail: aan.jain06@gmail.com

Copyright: (C) the author(s), publisher and licensee Medip Academy. This is an open-access article distributed under the terms of the Creative Commons Attribution Non-Commercial License, which permits unrestricted non-commercial use, distribution, and reproduction in any medium, provided the original work is properly cited.

\begin{abstract}
Background: Inflammation seems to play a very crucial role in the growth and progression of many cancers. It has been reported that a peripheral blood count has been used as a cost-effective and simple parameter of systemic inflammation in critically ill patients. The aim of this study is to investigate whether components of WBC counts can predict the prognosis of patients with cervical cancer.

Methods: Medical records of 549 cervical cancer patients diagnosed between 1 January 2008 to 31 December 2008 were retrospectively analyzed. Receiver operating characteristic curve analysis and Cox proportional hazards model were applied to evaluate the effect of white blood cell (WBC) counts on overall survival.

Results: The 5-year overall survival of the cohort was found to be $67.7 \%$. On the basis of univariate analysis elevated monocyte count $\left(\geq 0.51510^{9} / \mathrm{L}\right)$ and lower lymphocyte count $\left(\leq 2.07510^{9} / \mathrm{L}\right)$ were associated with poor overall survival (OS) $(\mathrm{p}=0.016$ and 0.002 respectively). Multivariate Cox proportional hazard analysis showed that higher monocyte and lower lymphocyte levels were a significant independent predictors for worse OS $(\mathrm{HR}=1.555,95 \% \mathrm{CI}$ $=1.125-2.149 ; \mathrm{P}=0.008)$ and $(\mathrm{HR}=1.712,95 \% \mathrm{CI}=1.232-2.379 ; \mathrm{P}=0.001)$ respectively. The advanced overall stage and treatment were also found to be independent indicators for poor OS.

Conclusions: Pretreatment monocyte and lymphocyte count is an independent predictor of prognosis in cervical cancer patients. Thus it may be a cost effective marker to predict the outcome of cervical cancer patients.
\end{abstract}

Keywords: Cervical cancer, Survival, Monocyte, Lymphocyte

\section{INTRODUCTION}

Cervical cancer is an important health issue in developing countries. In India, there were $1,22,844$ new cases of cancer of cervix uteri in the year 2012 with age specific incidence rate of 22 per 100,000 and age specific mortality rate of 12.4 per $100,000 .{ }^{1}$ Although incidence and mortality rates have reduced but cervical cancer is still the second leading site of cancer incidence and mortality among women in India as well as in developing world. ${ }^{1}$ In India in spite of the improvement in cancer care, prognosis of cervical cancer remains poor as compared to other Asian countries such as China, Thailand, South Korea and Singapore. ${ }^{2}$
Therefore, study of prognostic factors related to cervical cancer incidence and prognosis is of great significance.

Parametrial infiltration, lymph node involvement, depth of invasion, surgical margin, number of positive lymph node and lymphovascular space involvement (LVSI) were found to be independent predictors of overall survival and recurrence in cervical cancer patients. ${ }^{3,4}$ But unfortunately these factors can be accessed only after surgery and in cervical cancer main treatment modality is radiotherapy or radiotherapy with chemotherapy. Therefore, a low-cost, standardized and reliable marker is required to be evaluated for its possible prognostic role in cervical cancer patients. In cervical cancer, it has been suggested that host immunological factors have an impact 
on treatment response and prognosis. ${ }^{5}$ Increased release of pro-inflammatory cytokines produces a systemic inflammatory response reflected in changes in circulating markers of inflammation, such as C-reactive protein and white blood cells. ${ }^{6,7}$

There are several studies to date suggesting that the total white blood cell count as well as its components, such as neutrophils, lymphocytes and monocytes can predict survival in many cancers, including cervical cancer, oral cavity, breast cancer, gastric cancer, hepatocellular carcinoma, Hodgkin's lymphoma and lung cancer., ${ }^{5,8-15}$ However, in cervical cancer, information regarding the prognostic implications of tumor related leukocytosis is limited. ${ }^{16}$

Keeping this in view, we carried out a retrospective cohort study to understand the role of total and differential WBC counts in overall survival of cervical cancer patients. The study had the approval of the research ethics committee of the hospital.

\section{METHODS}

The medical records of 549 cervical cancer patients, diagnosed at Tata Memorial Hospital between 1 January 2008-31 December 2008 and who had received treatment, were analyzed retrospectively. Data on pre-treatment routine laboratory measurements of white blood cells (WBC), including neutrophil counts, lymphocyte counts and monocyte counts were retrospectively collected from medical records. In addition, data on age at diagnosis, tumor histology, types of treatment received and status of the patient (alive/dead) at the time of analysis was also retrieved from the hospital medical records.

The most appropriate cut-off points for the counts of total WBC, neutrophil, lymphocyte and monocyte was chosen by receiver operating characteristic (ROC) curves to stratify patients at a high risk death. The score at the point with both maximum sensitivity and specificity was selected as the best cut-off value. Comparison between the two stratums was done by using Mann-Whitney test for continuous data such as age and summary measures was reported as median with range. Frequency counts and proportions were calculated for categorical data such as stage, histology and treatment modality, and comparison was done by using chi-square test.

In survival analysis, overall survival time was defined as time from diagnosis until death; the follow-up of patients still alive has been censored at their latest date of followup. Survival curves were made by the Kaplan-Meier method and compared by the log-rank test. The Cox proportional hazards model was applied for univariate and multivariate (backward method) analysis to identify prognostic factors. Statistical analyses were performed using SPSS software v17.0. A p-value of less than or equal to 0.05 was considered as statistically significant.

\section{RESULTS}

The patients' characteristics are summarized in Table 1. As shown, the median age was 50 years (range from 2382 years). Out of the total 549 patients, $275(50.09 \%)$ were diagnosed at late stages (III and IV), and 274 patients $(49.91 \%)$ were at early stages (I and II). 496 (90.3\%) patients had squamous cell carcinoma (SCC) while the rest $53(9.7 \%)$ had histology other than SCC. The 3 year and 5 year overall survival of the cohort was $72.3 \%$ and $67.7 \%$ respectively.

The cut-off value of total WBC, neutrophil, lymphocyte and monocyte counts for survival outcomes were determined by ROC curves. The total WBC cut-off point of 8.82 was selected for the survival analyses and all patients were divided into either high $\left(\mathrm{WBC}>8.82 \times 10^{9} / \mathrm{L}\right)$ or low WBC $\left(\mathrm{WBC} \leq 8.82 \times 10^{9} / \mathrm{L}\right)$ groups. Similarly neutrophil count of $5.345 \times 10^{9} / \mathrm{L}$, lymphocyte count of $2.075 \times 10^{9} / \mathrm{L}$ and monocyte count of $0.515 \times 10^{9} / \mathrm{L}$ were taken as the optimal cut-off points for survival analysis.

\section{Table 1: Patient's characteristics.}

\begin{tabular}{|lll|}
\hline Characteristic & Number & $\begin{array}{l}\text { Percentage/ } \\
\text { range }\end{array}$ \\
\hline Number of patients & 549 & \\
\hline Median age, years (range) & 50 & $23-82$ \\
\hline Median white cell count, $\times 10^{9} / \mathrm{L}$ & 8.80 & $2.78-34.7$ \\
\hline Median neutrophil count, $\times 10^{9} / \mathrm{L}$ & 5.35 & $1.12-25.00$ \\
\hline Median lymphocyte count, $\times 10^{9} / \mathrm{L}$ & 2.08 & $0.46-5.95$ \\
\hline Median monocyte count, $\times 10^{9} / \mathrm{L}$ & 0.52 & $0.05-2.07$ \\
\hline FIGO stage & & \\
\hline I & 57 & 10.4 \\
\hline II & 217 & 39.5 \\
\hline III & 241 & 43.9 \\
\hline IV & 34 & 6.2 \\
\hline Cell type & & \\
\hline Squamous & 496 & 90.3 \\
\hline Non squamous & 53 & 9.7 \\
\hline Treatment & & \\
\hline Others (S/S+RT/S+RT+CT) & 61 & 11.1 \\
\hline RT only & 213 & 38.8 \\
\hline RT+CT & 275 & 50.1 \\
\hline Abbreviatons: S-surgery, RT-- & & \\
\hline
\end{tabular}

Abbreviations: S-surgery, RT-radio therapy, CT-chemo therapy.

Age, stage, histology, treatment modality, total WBC count, neutrophil count, lymphocyte count and monocyte count were analysed for identification of factors associated with cervical cancer prognosis. Univariate analysis revealed that age $(>50$ years; $p=0.031)$, lymphocyte $(\leq 2.075 ; \mathrm{p}=0.002)$, monocyte $(\geq 0.515 ; \mathrm{p}=$ $0.016)$, late stage at diagnosis $(\mathrm{p}<0.001)$ and treatment modality $(\mathrm{p}<0.001)$ were associated with poor prognosis. All the characteristics which were found to be significant in univariate analysis such as age, stage, treatment modality, lymphocyte count and monocyte count were included in the multivariate analysis. The results showed 
that higher monocyte $(\mathrm{HR}=1.555,95 \% \mathrm{CI}=1.125$ $2.149 ; \mathrm{p}=0.008)$ and lower lymphocyte counts $(\mathrm{HR}=$
$1.712,95 \% \mathrm{CI}=1.232-2.379 ; \mathrm{p}=0.001)$ retained their prognostic effect after adjusting for other co-variates.

Table 2: Comparison of patients' characteristics according to monocyte cut off of $0.515\left(\times 10^{9} / \mathrm{L}\right)$ and lymphocyte cut off of $2.075\left(\times 10^{9} / \mathrm{L}\right)$.

\begin{tabular}{|c|c|c|c|c|c|c|}
\hline \multirow[b]{2}{*}{ Characteristics } & \multicolumn{2}{|c|}{ Monocyte (×10\%/L) } & \multirow[t]{2}{*}{ P value } & \multicolumn{2}{|c|}{ Lymphocyte (×109/L) } & \multirow[t]{2}{*}{ P value } \\
\hline & $\begin{array}{l}<0.515 \\
(n=273)\end{array}$ & $\begin{array}{l}\geq 0.515 \\
(n=276)\end{array}$ & & $\leq 2.075(\mathrm{n}=274)$ & $>2.075(\mathrm{n}=275)$ & \\
\hline Median age, years (range) & 50 & 51 & 0.260 & 50 & 51 & 0.084 \\
\hline FIGO stage, n (\%) & & & 0.135 & & & $0.007 * *$ \\
\hline I-II & $145(53.1)$ & $129(46.7)$ & & $121(44.2)$ & $153(55.6)$ & \\
\hline III-IV & $128(46.9)$ & $147(53.3)$ & & $153(55.8)$ & $122(44.4)$ & \\
\hline Cell type, n (\%) & & & 0.103 & & & 0.675 \\
\hline Squamous & $241(88.3)$ & $255(92.4)$ & & $249(90.9)$ & $247(89.8)$ & \\
\hline Non-squamous & $32(11.7)$ & $21(7.6)$ & & $25(9.1)$ & $28(10.2)$ & \\
\hline Treatment & & & 0.092 & & & 0.052 \\
\hline Others $(\mathrm{S} / \mathrm{S}+\mathrm{R}+\mathrm{S}+\mathrm{R}+\mathrm{C})$ & $38(13.9)$ & $23(8.3)$ & & $34(12.4)$ & $27(9.8)$ & \\
\hline RT only & $136(49.8)$ & $114(41.3)$ & & $117(42.7)$ & $96(34.9)$ & \\
\hline $\mathrm{RT}+\mathrm{CT}$ & $99(36.3)$ & $139(50.4)$ & & $123(44.9)$ & $152(55.3)$ & \\
\hline
\end{tabular}

**5\% level of significance. Abbreviations: S-Surgery, RT-Radio therapy, CT-Chemo therapy.

Table 3: Bi-variate and multivariate analysis for identifying prognostic factors for overall survival (OS).

\begin{tabular}{|c|c|c|c|c|}
\hline & Univariate & & Multivariate & \\
\hline Parameter & HR (95\% CI) & $\mathrm{p}$ value & HR $(95 \%$ CI $)$ & $\mathrm{p}$ value \\
\hline \multicolumn{5}{|l|}{ Age } \\
\hline$\leq 50$ years & 1 & & - & 0.080 \\
\hline$>50$ years & $1.412(1.033-1.930)$ & $0.031 * *$ & & \\
\hline \multicolumn{5}{|l|}{ Neutrophil } \\
\hline$<5.345$ & 1 & & - & \\
\hline$\geq 5.345$ & $1.315(0.962-1.799)$ & 0.086 & & \\
\hline \multicolumn{5}{|l|}{ Lymphocyte } \\
\hline$>2.075$ & 1 & & 1 & \\
\hline$\leq 2.075$ & $1.658(1.206-2.281)$ & $0.002 * *$ & $1.712(1.232-2.379)$ & $0.001 * *$ \\
\hline \multicolumn{5}{|l|}{ Monocyte } \\
\hline$<0.515$ & 1 & & 1 & \\
\hline$\geq 0.515$ & $1.472(1.075-2.016)$ & $0.016^{* *}$ & $1.555(1.125-2.149)$ & $0.008 * *$ \\
\hline \multicolumn{5}{|l|}{ WBC count } \\
\hline$<8.82$ & 1 & & - & \\
\hline$\geq 8.82$ & $1.299(0.950-2.225)$ & 0.101 & & \\
\hline \multicolumn{5}{|l|}{ Stage } \\
\hline Early stage & 1 & & 1 & \\
\hline Late Stage & $1.857(1.352-2.550)$ & $<0.001 * *$ & $1.493(1.075-2.075)$ & $0.017 * *$ \\
\hline \multicolumn{5}{|l|}{ Cell type } \\
\hline Squamous & 1 & & - & \\
\hline Non-Squamous & $1.015(0.596-1.728)$ & 0.958 & & \\
\hline Treatment & & $<0.001 * *$ & & \\
\hline Others $(\mathrm{S} / \mathrm{S}+\mathrm{R} / \mathrm{S}+\mathrm{R}+\mathrm{C})$ & 1 & & 1 & \\
\hline RT only & $4.641(2.147-10.033)$ & $<0.001 * *$ & $3.348(1.506-7.441)$ & $0.003 * *$ \\
\hline $\mathrm{RT}+\mathrm{CT}$ & $1.902(0.873-4.146)$ & 0.106 & $1.484(0.666-3.308)$ & 0.335 \\
\hline
\end{tabular}

**5\% level of significance. Abbreviations: S-Surgery, RT-Radio therapy, CT-Chemo therapy, HR-Hazard ratio, CI-Confidence interval. 
Thus monocyte and lymphocyte counts were found to be independent predictors for overall survival of cervical cancer patients (Table 3).

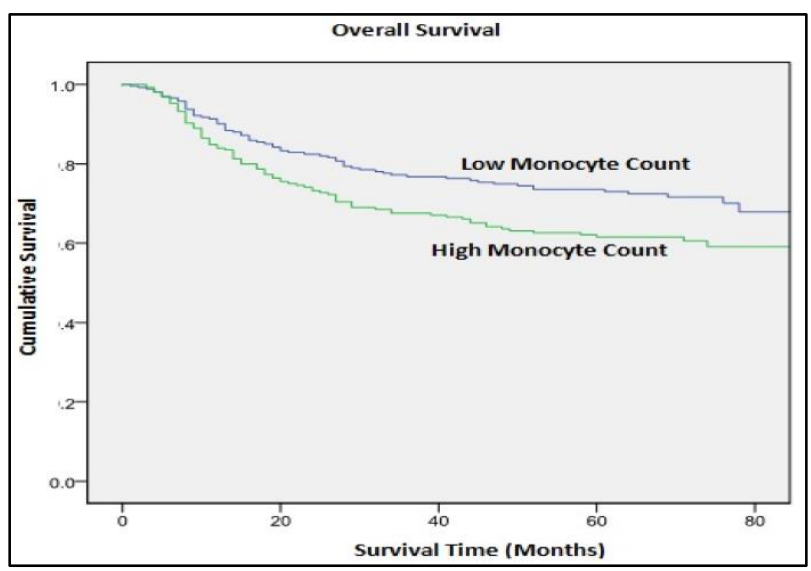

Figure 1: Kaplan-Meir curve for overall survival in cervical cancer patients classified into two groups according to monocyte counts.

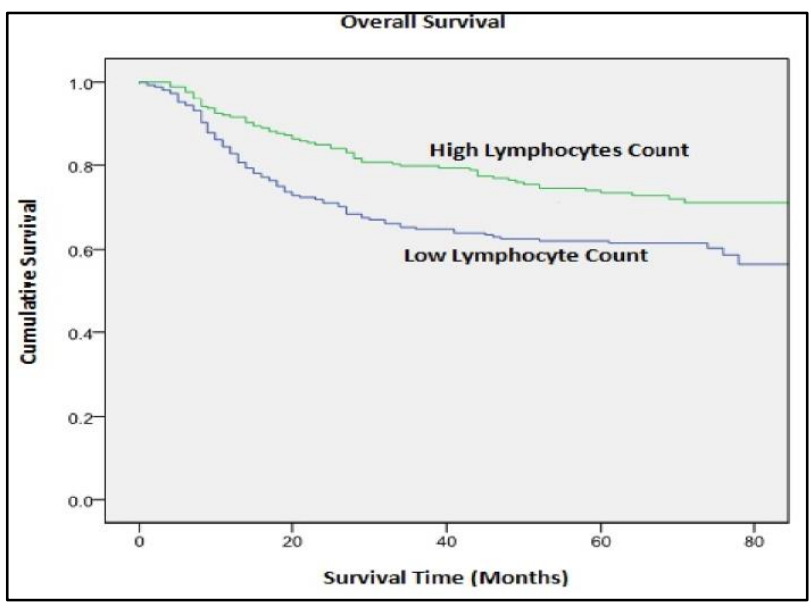

Figure 2: Kaplan-Meir curve for overall survival in cervical cancer patients classified into two groups according to lymphocyte counts.

The 5 year survival rate of patients with high monocyte count $\left(\geq 0.515 \times 10^{9} / \mathrm{L}\right)$ was found to be $61.6 \%$ and which was significantly $(\mathrm{p}=0.016)$ less than survival rate of $73.5 \%$ for patients with lower monocyte count (Figure 1). Similarly, 5 year survival rate for patients with higher $(>2.075)$ and lower lymphocyte counts was $73.44 \%$ and $62.0 \%$ respectively $(\mathrm{p}=0.002)$ (Figure 2$)$.

Patient characteristics were categorized as per high/low monocyte and lymphocyte counts (Table 2). None of the characteristic was found to be associated among low monocyte $\left(<0.515 \times 10^{9} / \mathrm{L}\right)$ group and high monocyte $\left(\geq 0.515 \times 10^{9} / \mathrm{L}\right)$ groups. When comparison was made for high $\left(>2.075 \times 10^{9} / \mathrm{L}\right)$ and low lymphocyte counts $\left(\leq 2.075 \times 10^{9} / \mathrm{L}\right)$, stage $(\mathrm{p}=0.007)$ was found to be significantly different.

\section{DISCUSSION}

Prognostic factors of clinical outcomes in patients with cancer are a useful tool in the practice of medicine, especially in the fields of oncology. Thus, availability of an universal prognostic factor will help to simplify the management of cancer patients. ${ }^{17}$ There is ample evidence suggesting that outcome in cancer patients is greatly affected by immune response and pre-treatment measure of inflammatory immune response can be used to independently predict survival of cancer patients. ${ }^{18,21,22}$ Total and differential WBC count is one of the most easily accessible markers of inflammation and many recent studies in cancers provide evidence that there is an interconnection between pre-treatment WBC counts and overall (OS) and disease free cancer survival (DFS). ${ }^{10-15}$ In this study, we have made an attempt to study the prognostic role of WBC counts and its differentials with other clinical factors. Our results confirmed the previous findings that factors such as stage and treatment were associated with prognosis for cervical cancer patients. ${ }^{8,23}$

The major findings of our study was that a higher absolute monocyte and lower lymphocyte pretreatment counts were significantly associated with poor overall survival and were independent of other variables to predict the prognosis for cervical cancer patients. These results were in accordance with other published literature probing the role of monocyte count and lymphocyte count in prognostication of cervical cancer patients. $5,8,9$ Recently, Sajadieh et al reported that a higher number of circulating monocytes can independently predict mortality (hazard ratio [HR], 1.13; 95\% CI, 1.06-1.19) as well as incident cancer (HR, 1.12; 95\% CI, 1.05-1.19) in a healthy population. ${ }^{24}$ Matsuo $\mathrm{K}$ et al found that elevated monocyte counts when compared to lower counts were significantly associated with an increased risk of $>50 \%$ myometrial tumor invasion, pelvic lymph node metastasis and advanced-stage. They also found that elevated monocyte counts were associated with decreased disease free survival ( 5 year rates, $71.0 \%$ versus $84.5 \%, \mathrm{p}=0.001$ ) and overall survival $(77.2 \%$ versus $89.3 \%, \mathrm{p}<0.001)$ and in multivariate analysis, elevated monocyte counts remained an independent prognostic factor for decreased disease-free (HR 1.74, 95\% CI 1.02-2.96, p=0.041) and overall (HR 2.63, 95\% CI 1.37-5.05, $\mathrm{p}=0.004$ ) survival. $^{25}$ Similarly absolute monocyte count has been reported to be independent prognostic indicator for breast cancer, stomach cancer, Hodgkin's lymphoma, colorectal cancer and ovarian cancer. ${ }^{11,12,14,26,27}$ These studies provide evidence that monocytes are immunologically relevant host factors that can be routinely assessed through the CBC count to monitor patients' response to treatment and identify high-risk patients who are more likely to have adverse outcomes.

The exact underlying mechanism explaining the association between elevated number of monocyte and unfavorable cancer prognosis has not been elucidated. However, a possible explanation can be that monocytes 
secrete various pro-inflammatory cytokines, such as interleukin (IL)-1, IL-6, IL-10 and tumor necrosis factor (TNF- $\alpha$ ), which have been associated with shorter survival and worse prognosis in malignances. ${ }^{28,29}$ Moreover, monocytes upon stimulation are known to release monocyte chemo-attractant protein (MCP-1)-1 and mediate tumor associated macrophage infiltration in solid tumors, which could produce a variety of chemokines such as transforming growth factor (TGF- $\alpha$ ), IL-1 and IL-6 to promote tumorigenesis, angiogenesis and distant metastasis of malignant tumors. ${ }^{29,30}$ Further, studies have linked monocyte with an increased number of bone marrow-derived myelomonocytic cells, these cells infiltrate the tumor and differentiate into tumorassociated macrophages, which in turn release many angiogenic factors and have been shown to be associated with poor prognosis in cancers. ${ }^{29,31}$

In this study, it was found that pretreatment lower absolute lymphocyte count (ALC) was associated with poor prognosis. This finding is in agreement with previous studies conducted to assess the role of lymphocyte counts as a prognostic factor in cervical cancer patients. ${ }^{5,9}$ Similarly, ALC has been associated with prognosis of number of cancer such as lymphoma, breast cancer, lung cancer, and ovarian cancer. ${ }^{32,33}$ Hence over the years, ALC is proven to be an independent prognostic factor for survival, independent of cancer type, and it is included in several validated prognostic scores. ${ }^{17,34}$ Although the actual mechanisms of the association between low lymphocyte count and poor prognosis is unclear, a possible explanation can be that circulating lymphocyte secrete cytokines, which prevent proliferation and metastasis of tumor cells and have an important function in cytotoxicity. ${ }^{35}$ An increased number of tumor-infiltrating lymphocytes (TILs) is correlated with a favorable prognosis in cancer. ${ }^{36}$ Cluster-ofdifferentiation $(\mathrm{CD} 8+) \mathrm{T}$ cells have a pivotal role in tumor growth control by cytotoxic T-cell killing and apoptosis and (CD4+) $\mathrm{T}$ cells play a central role in orchestrating the immune response to cancers. ${ }^{37-39}$ Thus these roles of lymphocyte is substantiated by the fact that subsets of lymphocytes, such as CD4+, CD8+, CD3-, and CD56+ $\mathrm{T}$ cells, were found to be reduced in patients with advanced disease, despite the increased white blood cells in advanced stages. ${ }^{40}$ Thus, a decreased number of lymphocytes may result in an inadequate cell-mediated immunologic response towards the tumor.

There were certain limitations of our study which need to be acknowledged. The study was conducted at a single institution, was of retrospective nature and relies on clinical data not primarily meant for research. These drawbacks emphasize the need for conducting multicenter prospective studies to completely understand the role of white blood cell count in cervical cancer survival.

\section{CONCLUSION}

In conclusion, we have demonstrated that pre-treatment higher monocyte and lower lymphocyte counts may be an indicator of poor prognosis in patients with cervical cancer. Since, complete blood count test is cost effective, easily accessible and reproducible, the pre-treatment circulating monocyte and lymphocyte count can be used as a prognostic factor in clinical practices.

\section{Funding: No funding sources}

Conflict of interest: None declared

Ethical approval: The study was approved by the Institutional Ethics Committee

\section{REFERENCES}

1. Ferlay J, Soerjomataram I, Ervik M, Dikshit R, Eser S, Mathers C, et al. GLOBOCAN 2012 v 1.0, cancer incidence and mortality Worldwide: IARC Cancer Base No. 11. Lyon, France: International Agency for Research on Cancer; 2013. Available at http://globocan.iarc.fr. Accessed 3 August 2015.

2. Sankaranarayanan R, Swaminathan R, Brenner H, Chen K, Chia KS, Chen JG, et al. Cancer survival in Africa, Asia, and Central America: a populationbased study. Lancet Oncol. 2010;11:165-73.

3. Delgado G, Bundy B, Zaino R, Sevin BU, Creasman WT, Major F. Prospective surgical pathological study of disease-free interval in patients with stage IB squamous cell carcinoma of the cervix: a Gynecologic Oncology Group study. Gynecol Oncol. 1990;38:352-7.

4. Ho CM, Chien TY, Huang SH, Wu CJ, Shih BY, Chang SC. Multivariate analysis of the prognostic factors and outcomes in early cervical cancer patients undergoing radical hysterectomy. Gynecol Oncol. 2004;93:458-64.

5. Hoskin PJ, Rojas AM, Peiris SN, Mullassery V, Chong IY. Pre-treatment haemoglobin and peripheral blood lymphocyte count as independent predictors of outcome in carcinoma of cervix. Clin Oncol (R Coll Radiol). 2014;26:179-84.

6. Saito K, Tatokoro M, Fujii Y, Iimura Y, Koga F, Kawakami $\mathrm{S}$, et al. Impact of $\mathrm{C}$ reactive protein kinetics on survival of patients with metastatic renal cell carcinoma. Eur Urol. 2009;55:1145-53.

7. Toriola AT, Grankvist K, Agborsangaya CB, Lukanova A, Lehtinen M, Surcel HM. Changes in pre-diagnostic serum C-reactive protein concentrations and ovarian cancer risk: a longitudal study. Ann Oncol. 2011;22:1916-21.

8. Lee YY, Choi CH, Sung CO, Do IG, Huh SJ, Song $\mathrm{T}$, et al. Prognostic value of pre-treatment circulating monocyte count in patients with cervical cancer: Comparison with SCC-Ag level. Gynecologic Oncology. 2012;124:92-7.

9. Choi CH, Kang H, Kim WY, Kim TJ, Lee JW, Huh SJ, et al. Prognostic value of baseline lymphocyte count in cervical carcinoma treated with concurrent 
chemoradiation. Int J Radiat Oncol Biol Phys. 2008;71:199-204.

10. Tsai YD, Wang CP, Chen CY, Lin LW, Hwang TZ, $\mathrm{Lu} \mathrm{LF}$, et al. Pretreatment circulating monocyte count associated with poor prognosis in patients with oral cavity cancer. Head Neck. 2014;36:947-53.

11. Hornychova' H, Melichar B, Toms`ova' M, Mergancova' J, Urminska' H, Ryska A et al. Tumorinfiltrating lymphocytes predict response to neoadjuvant chemotherapy in patients with breast carcinoma. Cancer Investigation. 2008;26:1024-31.

12. Bruckner HW, Lavin PT, Plaxe SC, Storch JA, Livstone EM. Absolute granulocyte, lymphocyte, and moncyte counts. Useful determinants of prognosis for patients with metastatic cancer of the stomach. JAMA. 1982;247:1004-06.

13. Chew V, Chen J, Lee D, Loh E, Lee J, Lim KH. Chemokine-driven lymphocyte infiltration: an early intra-tumoural event determining long-term survival in resectable hepatocellular carcinoma. Gut. 2012;61:427-38.

14. Koh YW, Kang HJ, Park C, Yoon DH, Kim S, Suh C et al. The ratio of the absolute lymphocyte count to the absolute monocyte count is associated with prognosis in Hodgkin's lymphoma: correlation with tumor-associated macrophages. Oncologist. 2012;17:871-80.

15. Tibaldi C, Vasile E, Bernardini I, Orlandini C, Andreuccetti M, Falcone A. Baseline elevated leukocyte count in peripheral blood is associated with poor survival in patients with advanced nonsmall cell lung cancer: a prognostic model. J Cancer Res Clin Oncol. 2008;134:1143-9.

16. Mabuchi S, Matsumoto Y, Isohashi F, Yoshioka Y, Ohashi H, Morii E, et al. Pretreatment leukocytosis is an indicator of poor prognosis in patients with cervical cancer. Gynecologic Oncology. 2011;122:25-32.

17. Rochet NM, Markovic SN, Porrata LF. The role of complete blood cell count in prognosis-watch this space! Oncology and Hematology Review. 2012;8:76-82.

18. Stone HB, Peters LJ, Milas L. Effect of host immune capability on radiocurability and subsequent transplantability of a murine fibrosarcoma. J Natl Cancer Inst. 1979;63:1229-35.

19. Demaria S, Formenti SC. Sensors of ionizing radiation effects on the immunological microenvironment of cancer. Int $\mathrm{J}$ Radiat Biol. 2007;83:819-25.

20. Lorimore SA, Coates PJ, Scobie GE, Milne G, Wright EG. Inflammatory-type responses after exposure to ionizing radiation in vivo: a mechanism for radiation-induced bystander effects? Oncogene. 2001;20:7085-95.

21. Apetoh L, Ghiringhelli F, Tesniere A, Obeid M, Ortiz C, Criollo A, et al. Toll-like receptor 4dependent contribution of the immune system to anticancer chemotherapy and radiotherapy. Nat Med. 2007;13:1050-9.
22. Roxburgh CS, McMillan DC. Role of systemic inflammatory response in predicting survival in patients with primary operable cancer. Future Oncol. 2010;6:149-63

23. Lee YY, Choi CH, Kim HJ, Kim TJ, Lee JW, Lee $\mathrm{JH}$, et al. Pretreatment neutrophil: lymphocyte ratio as a prognostic factor in cervical carcinoma. Anticancer research. 2012;32:1555-62.

24. Sajadieh A, Mouridsen MR, Selmer C, Intzilakis T, Nielsen OW, Haugaard SB. Monocyte number associated with incident cancer and mortality in middle-aged and elderly community-dwelling Danes. Eur J Cancer. 2011;47:2015-22.

25. Matsuo K, Hom MS, Moeini A, Machida H, Takeshima N, Roman LD, et al. Significance of monocyte counts on tumor characteristics and survival outcome of women with endometrial cancer. Gynecologic Oncology. 2015;138:332-8.

26. Sasaki A, Kai S, Endo Y, Iwaki K, Uchida H, Tominaga $\mathrm{M}$, et al. Prognostic value of preoperative peripheral blood monocyte count in patients with colorectal liver metastasis after liver resection. J Gastrointest Surg. 2007;11:596-602.

27. Bishara S, Griffin M, Cargill A, Bali A, Gore ME, Kaye SB, et al. Pre-treatment white blood cell subtypes as prognostic indicators in ovarian cancer, Eur J Obstet Gynecol Reprod Biol. 2008;138:71-5.

28. Anand M, Chodda SK, Parikh PM, Nadkarni JS. Abnormal levels of pro-inflammatory cytokines in serum and monocyte cultures from patients with chronic myeloid leukemia in different stages, and their role in prognosis. Hematol Oncol. 1998;16:143-54.

29. Pollard JW. Tumour-educated macrophages promote tumour progression and metastasis. Nat Rev Cancer. 2004;4:71-8.

30. Hefler L, Tempfer C, Heinze G, Mayerhofer K, Breitenecker G, Leodolter S, et al. Monocyte chemoattractant protein-1 serum levels in ovarian cancer patients. Br J Cancer. 1999;81:855-9.

31. Dirkx AE, Oude Egbrink MG, Wagstaff J, Griffioen AW. Monocyte/macrophage infiltration in tumors: modulators of angiogenesis. J Leukoc Biol. 2006;80:1183-96.

32. Siddiqui M, Ristow K, Markovic SN, Witzig TE, Habermann TM, Colgan JP, et al. Absolute lymphocyte count predicts overall survival in follicular lymphomas. $\mathrm{Br} \quad \mathrm{J}$ Haematol. 2006;134:596-601.

33. Trédan O, Coquard IR, Chvetzoff G, Rebattu P, Bajard A, Chabaud S, et al. Validation of prognostic scores for survival in cancer patients beyond firstline therapy. BMC Cancer. 2011;11:95.

34. Hasenclever D, Diehl V. A prognostic score for advanced Hodgkin's disease. International prognostic factors project on advanced hodgkin's disease. N Engl J Med. 1998;339:1506-14.

35. Ding PR, An X, Zhang RX, Fang YJ, Li LR, Chen $\mathrm{G}$, et al. Elevated preoperative neutrophil to lymphocyte ratio predicts risk of recurrence 
following curative resection for stage IIA colon cancer. Int J Colorectal Dis. 2010;25:1427-33.

36. Visser KE, Eichten A, Coussens LM. Paradoxical roles of the immune system during cancer development. Nat Rev Cancer. 2006;6;24-37.

37. Napankangas UT, Soini Y, Paakko P. High number of tumour-infiltrating lymphocytes is associated with apoptosis in non-small cell lung carcinoma. APMIS. 2001;109:525-32.

38. Donnem T, Al-Shibli K, Andersen S, Al-Saad S, Busund LT, Bremnes RM. Combination of low vascular endothelial growth factor A (VEGFA)/VEGF receptor 2 expression and high lymphocyte infiltration is a strong and independent favorable prognostic factor in patients with nonsmall cell lung cancer. Cancer. 2010;116:4318-25.

39. Hiraoka K, Miyamoto M, Cho Y, Suzuoki M, Oshikiri T, Nakakubo Y, et al. Concurrent infiltration by $\mathrm{CD} 8+\mathrm{T}$ cells and $\mathrm{CD} 4+\mathrm{T}$ cells is a favourable prognostic factor in non-small-cell lung carcinoma Br J Cancer. 2006;94:275-80.

40. Ray-Coquard I, Cropet C, Van Glabbeke M, Sebban C, Cesne AL, Judson I, et al. Lymphopenia as a prognostic factor for overall survival in advanced carcinomas, sarcomas, and lymphomas. Cancer Res. 2009;69:5383-91.

Cite this article as: Jain A, Bobdey S, Sathwara J, Ganesh B, Saoba S, Khan A. Role of monocyte and lymphocyte counts in prognosis of cervical cancer. Int J Reprod Contracept Obstet Gynecol 2016;5:2243-9. 